This is an Accepted Manuscript version of the following article: Andrew E.G. Jonas \& Rüdiger K.W. Wurzel (2020) Climate urbanism and austerity in structurally disadvantaged cities, Urban Geography, DOI: 10.1080/02723638.2020.1840207.

It is deposited under the terms of the Creative Commons Attribution-NonCommercial License (http://creativecommons.org/licenses/by-nc/4.0/), which permits non-commercial re-use, distribution, and reproduction in any medium, provided the original work is properly cited.

\title{
Climate Urbanism and Austerity in Structurally Disadvantaged Cities
}

\begin{abstract}
If the governance challenges of climate change have been well researched for medium-sized, affluent and larger entrepreneurial cities, relatively little is known about climate urbanism in small-to-medium-sized cities experiencing long-term industrial decline, social deprivation and austerity. Such structurally disadvantaged cities often struggle to build inclusive new climate alliances, attract green jobs, and forge new images. This intervention argues that research on climate urbanism needs to consider two emerging trends in structurally disadvantaged cities: (1) how austerity is producing uneven geographies of climate urbanism; (2) the local social and economic conditions underpinning the construction of new climate alliances around alternative trajectories of urban development.
\end{abstract}

Key words: Climate urbanism, structurally disadvantaged cities, austerity, Europe

\section{Introduction}

Urban managers and politicians are not just responsible for economic development and social provision within their local jurisdiction but also have become key players in collective efforts to address global climate change or what urban geographers describe as 'climate urbanism' (Long \& Rice, 2019). In Europe, research on climate urbanism has examined local policy actions in relatively well-resourced, larger cities that are active in international climate networks (Bulkeley \& Kern, 2006; Kern \& Bulkeley, 2009). However, climate urbanism also has implications for the economic and social development of less well-connected, small-tomedium-sized European cities, many of which are dependent on high carbon-intensive sectors and yet at the same time must confront profound structural problems of high unemployment, population shrinkage, dependence on low-skill and contingent employment, 
social deprivation and austerity. In these 'structurally disadvantaged cities' (Jonas et al., 2017; Wurzel et al., 2019), the transition to a low-carbon economy around renewable energy sources (e.g. offshore wind farms) and green jobs (e.g. recycling, maintenance and repair) requires not just activating international climate networks but also profound changes in the local economy, governance institutions, climate alliances and place image.

In this brief contribution to the climate urbanism debate, we suggest that structurally disadvantaged cities contain strategic assets (e.g. functioning port facilities) and governance arrangements (e.g. active climate coalitions) that offer selective opportunities for transitioning to low-carbon forms of development notwithstanding current conditions of austerity. It draws upon ongoing research into a small sample of broadly comparable European maritime port cities in the United Kingdom, Germany, Denmark and the Netherlands. These cities share in common the following characteristics: free-standing places with strong local political identities; similar population size (small-to-medium sized cities up to 300,000 residents); relatively high unemployment rates; peripheral geographical locations within their national contexts; functioning port facilities; and historic dependence on maritime-related sectors such as fishing, oil and gas. Many of these cities also have high levels of intra-urban socio-economic deprivation, prompting progressive grassroots climate initiatives to target disadvantaged neighbourhoods and communities. In the remainder of the paper, we focus on two emerging trends in structurally disadvantaged cities: (1) how austerity produces uneven geographies of climate urbanism; and (2) the conditions underpinning the construction of new climate alliances around alternative trajectories of urban development.

\section{Uneven urban geographies of climate transition under conditions of austerity}

The rate at which cities are transitioning towards climate-friendly, carbon-neutral forms of development depends in part upon the presence (or absence) of state (or European Union) 
policy incentives and austerity measures. On the one hand, inter-urban competition for investment and state resources encourages urban managers and politicians in some cities to align climate action with mainstream economic sectors and social priorities (While et al., 2010). On the other hand, others are incentivized to pursue alternative green trajectories of urban development such as attracting investment around renewable energy (Jonas et al., 2011). At the same time, climate urbanism is transforming the economic rationale of interurban competition, empowering new coalitions between business and local government, and enabling various greening strategies to enter the mainstream of place marketing (Andersson \& James, 2018).

Nonetheless, we find that the strategic choices facing structurally disadvantaged maritime port cities in Europe are not so straightforward. Some are proving adept at capitalizing upon resources, skills and assets available in traditional sectors, especially ports and the oil and gas industries, in order to attract new investment in the renewables sector. Such cities now have a significant share - between 20 and 40 per cent in some cases - of recent (post-2010) growth in national employment in offshore wind energy and associated green jobs (production, port activities, skills, and servicing and repair). Others, however, have struggled to attract new investment in green jobs and, in fact, have even experienced recent job losses in green sectors such as renewable energy.

Further expansion of the offshore wind energy sector in Europe and globally remains highly sensitive to variations in environmental regulations (e.g. national and EU energy policy) and ongoing austerity measures, making some cities especially vulnerable to spatially uneven investment in the renewables sector. The recent experiences of Cuxhaven and Bremerhaven in Germany are indicative. Working in partnership with the state of Lower Saxony, the urban district of Cuxhaven is involved in the development and strengthening of offshore wind energy as a major pillar of the local economy. Whilst Cuxhaven has been the 
recipient of major investments in offshore wind energy, the hitherto important role played by Bremerhaven in this sector is threatened by a decision by Siemens Gamesa to develop new offshore wind farm production operations in Cuxhaven as well as in the port city of Hull in the United Kingdom (Wurzel et al., 2019).

\section{New climate alliances and the scope for alternative urban politics}

As with entrepreneurial cities, urban managers and politicians in structurally disadvantaged cities recognize the huge potential in pursuing (global) leadership on climate change and exposing inaction on the part of the nation state (Rice, 2010; Dierwechter, 2020). In many cases, the development of the offshore wind energy under conditions of fiscal austerity has stimulated stronger collaboration between business, local government and local educational and research institutions especially in certain structurally disadvantaged cities. For example, in 2011 the City of Bremerhaven embarked upon a business-led climate initiative branded as Kurs Klimastadt Bremerhaven or 'Course Climate City' which has since reached out to educational institutions and civil society organisations through theatres, schools and young people's councils. In Hull, by way of comparison, efforts by the City Council in the early 2010s to build an alliance around a more socially inclusive 'green vision for the city' soon gave way to a business-led regional economic development strategy mainly focussed around attracting investment in offshore renewable energy production and jobs (Jonas et al., 2017). Notwithstanding the more recent flourishing of grassroots climate activism in both cities, austerity remains a significant obstacle to local authority-led efforts to build socially inclusive climate alliances.

Nonetheless, given the extent of social deprivation found in neighbourhoods within structurally disadvantaged cities, local conditions are ripe for the flourishing of a range of grassroots green urban initiatives, such as transport and energy schemes, recycling, repair and 
reuse (circular economy), food security, and sustainable urban living. In the most socially deprived neighbourhoods of Hull, for example, social enterprise organisations have started to integrate local action around food security with the circular economy. Such initiatives require innovative ways of engaging the urban citizenry through grassroots educational programmes, cultural events and, increasingly, a range of social media platforms (Lekan \& Rogers, 2020). Austerity thus calls for long-term, socially sustainable grassroots climate action throughout neighbourhoods in structurally disadvantaged cities.

\section{Conclusions}

Climate policy is fast becoming a central pillar of what Phelps \& Miao (2020) call the 'new urban managerialism': how urban managers and politicians in cities - large and affluent as well as small-to-medium and poor - are adopting innovative responses to inter-urban competition, neo-liberal austerity and climate change. At the same time - and as recent debates have highlighted - there are certain limitations associated with building theory or making empirical generalizations from a few well-resourced, large and internationallynetworked cities at the expense of knowledge of urban climate transformations occurring in the vast corpus of peripheral small-to-medium sized places distributed around the world (Robinson, 2011; Bulkeley et al., 2015). In the latter cities, the traditional economic development activities of mainstream business-led growth coalitions might well be tempered by the presence of a vibrant alternative politics of urban development - or so it has been suggested (Williams \& Pendras, 2013).

Our interest is in how structurally disadvantaged cities adopt climate-friendly, carbonneutral pathways of urban economic development in addition to trying to attract offshore wind industry and other green economy investment, thereby steering the transition away from dependence on high carbon-intensive sectors and jobs. Across Europe, international climate 
policy actions are evidently forcing public officials and business elites in such cities to search for alternative renewable energy sources and green forms of economic development. Perhaps these do not amount to the scale of transformational changes necessary for addressing the global climate crisis in a socially just and sustainable manner (Leichenko and O’Brien, 2019). Nonetheless they provide a productive entry point for investigating the economic and social conditions under which structurally disadvantage cities might be steered along a transformational and more climate-friendly urban development pathway. If in this respect climate urbanism provides a select group of entrepreneurial cities opportunities for capital accumulation around new forms of consumption and growth (Long \& Rice, 2019), urban geographers still have much to learn from the experiences of structurally disadvantaged cities where the socially destructive effects of austerity and industrial decline are deeply entrenched in local communities and neighbourhoods.

\section{Acknowledgements}

We are very grateful to a reviewer for insightful comments which have prompted some revisions.

\section{References}

Andersson, Ida, \& James, Laura (2018). Altruism or entrepreneurialism? The co-evolution of green place branding and policy tourism in Växjö, Sweden. Urban Studies, 55(15), 34373453.

Bulkeley, Harriet, \& Betsill, Michelle (2005). Rethinking sustainable cities: multilevel governance and the 'urban' politics of climate change. Environmental Politics, 14(1), 42-63. Bulkeley, Harriet \& Kern, Kristine (2006). Local government and governing of climate change in Germany and the UK. Urban Studies, 43(12), 2237-2259. 
Bulkeley, Harriet, Castán Broto, Vanesa, \& Edwards, Gareth A.S. (2015). An urban politics of climate change. London: Routledge.

Dierwechter, Yonn (2020). 'Urbanisations' of green geopolitics: new state spaces in global unsustainability. Forthcoming in: Moisio, Sami, Koch, Natalie, Jonas, Andrew E.G., Lizotte, Christopher, \& Luukkonen, Juho (Eds.), Handbook on changing geographies of the state: new spaces of geopolitics. Cheltenham: Edward Elgar, 398-411.

Jonas, Andrew E.G., Gibbs, David, \& While, Aidan (2011). The New Urban Politics as a politics of carbon control. Urban Studies, 48(12), 2537-2544.

Jonas, A.E.G, Wurzel, Rüdiger, Monaghan, Elisabeth, \& Osthorst, Winfried (2017). Climate change, the green economy and re-imagining the city: the case of structurally disadvantaged European maritime port cities. Die Erde, 148(4), 197-211.

Kern, Kristine, \& Bulkeley, Harriet (2009). Cities, Europeanization and multi-level governance. Journal of Common Markets Studies, 47(1), 309-332.

Lekan, Malgorzata, \& Rogers, Heather (2020). Digitally-enabled diverse economies: exploring socially inclusive access to the circular economy in cities. Urban Geography, online first: https://doi.org/10.1080/02723638.2020.1796097

Leichenko, Robin, \& O’Brien, Karen (2019) Climate and society: transforming the future. Cambridge: Polity Press.

Long, Joshua, \& Rice, Jennifer, L. (2019). From sustainable urbanism to climate urbanism. Urban Studies, 56(5), 992-1008.

Phelps, Nicholas A., \& Miao, Julie T. (2020) Varieties of urban entrepreneurialism. Dialogues in Human Geography, online first: https://doi.org/10.1177/2043820619890438 Rice, Jennifer L. (2010). Climate, carbon, and territory: greenhouse gas mitigation in Seattle. Annals of the Association of American Geographers, 100(4), 929-937. 
Robinson, Jennifer (2011). Cities in a world of cities: the comparative gesture. International Journal of Urban and Regional Research, 35(1): 1-23.

While, Aidan, Jonas, Andrew E.G., \& Gibbs, David (2010). From sustainable development to carbon control. Transactions Institute of British Geographers, 35(1), 76-93.

Williams, Colin, \& Pendras, Mark (2013). Urban stasis and the politics of alternative development in the United States, Urban Geography, 34(3), 289-304.

Wurzel, Rüdiger, Moulton, Jeremy, Osthorst, Winfried, Mederake, Linda, Deutz, Pauline, \& Jonas, Andrew E.G. (2019). Climate pioneership and leadership in structurally disadvantaged maritime port cities. Environmental Politics, 28(1), 146-166. 